\title{
Does subgingival bacterial colonization differ between implants and teeth? A systematic review
}

\section{Belén RETAMAL-VALDES ${ }^{(a)}$ iD Marcio de Carvalho FORMIGA ${ }^{(a)}$ Mariana Linhares ALMEIDA(a) Aretuza FRITOLI(a) iD Kadmo Azevedo FIGUEIREDO(a) (iD Miriam WESTPHAL(a) ID \\ Patricia GOMES(a) \\ Magda FERES(a)}

(a) Universidade de Guarulhos - UNG, Dental Research Division, Department of Periodontology and Oral Implantology, Guarulhos, SP, Brazil.
Declaration of Interests: The authors certify that they have no commercial or associative interest that represents a conflict of interest in connection with the manuscript.

Corresponding Author:

Magda Feres

E-mail:mferes@ung.br

hitps://doi.org/10.1590/1807-3107bor-2019.vol33.0064

Submitted: June 11, 2019

Accepted for publication: June 13, 2019

Last revision: June 19, 2019

\begin{abstract}
The aim was of this study was to determine the current weight of evidence for the existence of specific differences between the microbiota of healthy teeth and healthy implants, or of teeth with periodontitis and implants with peri-implantitis. A systematic review was conducted according to the PRISMA statement. The MEDLINE, EMBASE and Cochrane databases were searched up to February 2018 for studies comparing microbiological data of biofilm samples collected from healthy teeth and implants or from teeth with periodontitis and implants with peri-implantitis. The weight of evidence was defined in three categories (strong, moderate and mild/some), according to the difference in number of studies showing statistically significantly higher counts and/or proportions and/or abundance and/or prevalence of microorganisms in health or in disease. Of the 132 articles identified, 8 were included. A wide range of microorganisms were present in different conditions but no microorganisms showed strong, moderate or mild/some evidence for a specific association with either teeth or implants. The results of this systematic review indicated that there is insufficient evidence in the literature to support specific differences between microorganisms colonizing teeth and implants, either in health or in disease.
\end{abstract}

Keywords: Peri-Implantitis; Periodontitis; Microbiota; Systematic Review.

\section{Introduction}

Peri-implantitis is a plaque-associated pathological condition characterized by inflammation of the peri-implant connective tissues and progressive loss of supporting bone. ${ }^{1}$ Peri-implantitis is not a rare event, ${ }^{2,3,4}$ and if not diagnosed and treated may lead to implant loss.

After some debate around the etiology of peri-implantitis, it has been well established that this is an infectious disease that share some similarities with periodontitis., 5 Previous Association studies evaluating the microbiota of healthy and diseased implants ${ }^{7,89}$ and a recent systematic review ${ }^{10}$ have suggested that established periodontal pathogens, such as Porphyromonas gingivalis, Treponema denticola and Tannerella forsythia are elevated in peri-implantitis in comparison with healthy implants. Despite this evidence, in the literature it is still unclear whether or not there are essential differences between the microbial profile of 
teeth and implants, and if there are pathogens or host-compatible species specifically associated with implant surfaces.

Understanding the microbiota associated with the onset and progression of an infection is a crucial step to studying the effectiveness of different treatments. Considering that the treatment of periodontal diseases has been extensively studied for over 50 years, understanding the similarities/differences between the microbiota colonizing teeth and implants may provide important information for the development of preventive and therapeutic strategies for peri-implantitis. Therefore, the aim of this systematic review was to determinate the current weight of evidence for the existence of specific microbiological differences between the subgingival biofilms around implants and teeth, in health and disease.

\section{Methods}

\section{Protocol and registration}

This systematic review was registered with the National Institute for Health Research PROSPERO, International Prospective Register of Systematic Reviews (registration number \#CRD42018093317) and conducted in accordance with the recommendations of the Preferred Reporting Items for Systematic Reviews and Meta-analysis (PRISMA) statement. ${ }^{11}$

\section{Focused question}

Are there specific differences in the composition of the subgingival/submucosal microbiota between teeth and implants, in health and disease?

\section{Eligibility criteria}

The studies were selected according to the following inclusion criteria:

a. Studies of any design comparing microbiological data obtained from subgingival/submucosal biofilm samples collected from patients with periodontitis and peri-implantitis;

b. Studies of any design that compared microbiological data obtained from subgingival/submucosal biofilm samples collected from patients with periodontal and peri-implant health.
Studies that met the following criteria were excluded:

a. Narrative or systematic reviews, meta-analyses, comments, editorials, letters to the editor, study protocols, case reports or case series;

b. Lack of a direct comparison of baseline microbiological data between periodontitis and peri-implantitis in case of prospective interventional studies;

c. Studies that evaluated only viruses;

d. Studies not presenting statistical analysis of the microbiological findings;

e. Studies evaluating healthy teeth or implants in patients with periodontitis.

\section{Search strategy, study selection and data collection}

The MEDLINE (through PubMed), EMBASE and Cochrane Library databases were searched up to February 19, 2018, by two independent reviewers (B.R-V. and M.Fe.) using MeSH terms and other keywords described in Table 1. In addition, a manual search was conducted based on the list of References of the selected manuscripts and other Review articles. Titles and abstracts of studies identified in the search were read independently by two researchers (M.L.A. and A.F.) and any disagreement was solved through discussion. If disagreement persisted, another researcher was consulted in order to achieve consensus (M.Fe.). After abstract reading, those studies that fulfilled the inclusion and exclusion criteria were read in full. Data extraction was conducted by four different independent researchers (B.R-V., K.A.F., M.Fo. and M.W.).

\section{Risk of bias in individual studies}

Two reviewers (M.Fo. and M.L.A.) appraised the risk of bias on the selected studies using the NIH Quality Assessment Tool for Observational Cohort and Cross-Sectional Studies. Cases of disagreement were solved by a third reviewer (M.Fe.).

\section{Additional analyses: weight of evidence}

Toestimate the weight of evidence for microorganisms associated with periodontitis and peri-implantitis and/ or periodontal and peri-implant health, the following categories were defined, according to differences in 
number of studies showing specific microorganisms in statistically significantly higher counts/proportions/ abundance/prevalence in each condition: a) Strong evidence: difference shown by $>5$ studies, b) Moderate evidence: difference shown by $3-5$ studies, and c) Mild/Some evidence: difference shown by 2 studies. ${ }^{12}$

\section{Summary measures}

The following information was collected from each study and registered in predefined forms: microbiological outcomes (e.g., microorganisms appraised, taxa in higher counts and/or proportions and/or abundance and/or prevalence in teeth or in implants [primary outcome of interest]), study design, characteristics of participants (e.g., age, proportion of men and smokers, case definition of periodontitis/peri-implantitis and periodontal/peri-implant health, mean plaque index, probing depth [PD], clinical attachment level, and number of sites with $P D \geq 5 \mathrm{~mm}$, $P D \geq 6 \mathrm{~mm}$ and $\mathrm{PD} \geq 7 \mathrm{~mm}$ ), as well as number of samples collected, sampling strategy, diagnostic method used and data expression. For longitudinal observational/interventional studies, only baseline data were collected.

\section{Results}

\section{Studies included}

The flow chart of the study is represented in Figure 1. The electronic search (Table 1) detected a total of 107 articles. After title and abstract screening, 91 articles were excluded and 16 were selected for full-text reading. During the manual search, no additional articles were selected. Eight articles were excluded after full-text reading: six articles did not directly compare microbiological data from healthy teeth with healthy implants, or periodontitis and peri-implantitis ${ }^{5,7,9,13,14,15,16}$ and two studies did not present statistical analysis comparing periodontal and peri-implant health or disease (Table 2). ${ }^{17,18}$ Therefore, 8 articles were included in the current systematic review. $19,20,21,22,23,24,25,26$

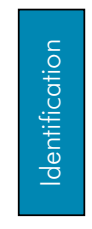

Records identified through database searching (PubMed 107, EMBASE 25, Cochrane 0)
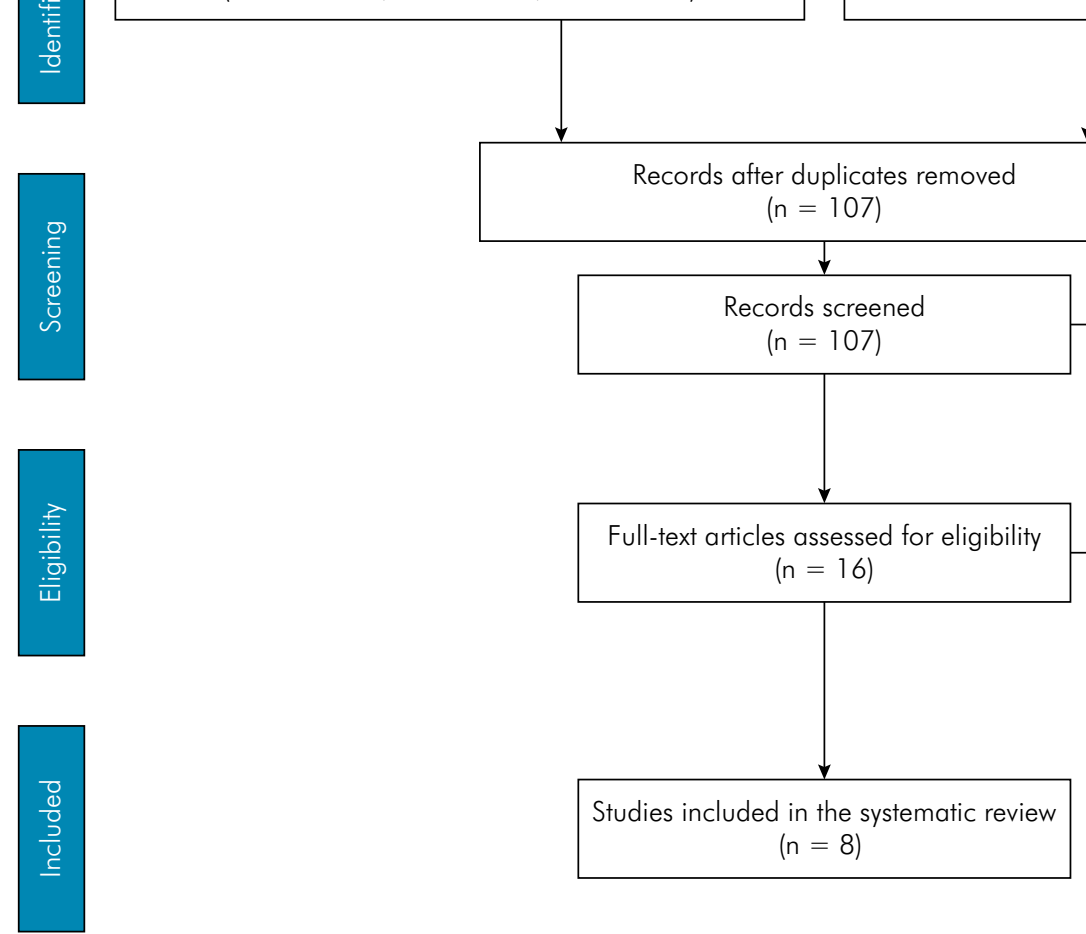

Additional articles identified through hand search $(n=0)$

Figure 1. Flow chart of paper selection. 
Table 1. Search strategy.

\begin{tabular}{ccc}
\hline & Terms used & Number of studies \\
\hline \multicolumn{4}{c}{ (peri-implantitis OR peri implantitis OR diseased implants OR peri-implant disease OR periimplant disease } \\
OR mucositis OR healthy implants OR dental implant OR osseointegrated implant) \\
AND $\quad \begin{array}{c}\text { (periodontitis OR periodontal disease OR periodontal infection OR periodontal diseases OR aggressive } \\
\text { periodontitis OR chronic periodontitis OR periodontal health OR healthy periodontium OR periodontally } \\
\text { healthy OR healthy teeth) }\end{array}$ \\
AND & (subgingival sample OR plaque sample OR biofilm sample OR subgingival biofilm) & 107 \\
\hline
\end{tabular}

Table 2. Reasons for exclusion.

\begin{tabular}{|c|c|}
\hline Exclusion reason & References \\
\hline $\begin{array}{l}\text { It did not directly compare microbiological data from healthy } \\
\text { teeth and healthy implants, or periodontitis and peri-implantitis }\end{array}$ & $\begin{array}{l}\text { Meijndert et al. }(2010)^{5} \text {; Ata-Ali et al. }(2015)^{7} \text {; Stokman et al. }(2017)^{9} \text {; } \\
\text { Apatzidou et al. }(2017)^{13} ; \text { Nelson \& Thomas }(2010)^{14} \text {; Zhang et al. }(2015)^{16}\end{array}$ \\
\hline No statistical analyses of the data presented & Koyanagi et al. $(2010)^{18}$; Koyanagi et al. $(2013)^{17}$ \\
\hline
\end{tabular}

\section{Methodological features of the studies included and demographic characteristics of the population evaluated}

Table 3 presents the methodological features of the studies included and demographic characteristics of the populations evaluated. Seven studies were cross-sectional and one was a longitudinal cohort. The mean age of the studied volunteers ranged between 35.5-60.1 years old. Two studies included smokers. ${ }^{25,26}$ Different clinical criteria were used to define periodontal and peri-implant health, periodontitis and peri-implantitis. Two articles did not describe the inclusion criteria of the volunteers. ${ }^{21,24}$ A total of 102 individuals with periodontal and peri-implant health and 68 subjects with periodontitis and peri-implantitis were assessed (data not shown). The clinical characteristics of the studies volunteers are presented in Table 4.

Methodological features related to sampling and microbiological analysis are presented in Table 5. A total of 553 subgingival/submucosal biofilm samples were evaluated (periodontal health $=137$, peri-implant health $=158$, periodontitis $=131$, peri-implantitis $=127$ ). In six studies ${ }^{19,20,21,24,25,26}$ the samples were collected and processed individually, and in two studies ${ }^{22,23}$ they were pooled. One study used culture ${ }^{24}$ one used Checkerboard DNA-DNA Hybridization, ${ }^{21}$ one used real time $\mathrm{PCR},{ }^{19}$ and five studies used sequencing/pyrosequencing ${ }^{20,22,23,25,26}$ for microbial identification.

\section{Microbiological data}

The microorganisms found in statistically significantly higher counts/proportions/abundance/ prevalence in the different periodontal and peri-implant conditions are presented in Table 6. Fifty taxa ( 25 bacterial species, 23 bacterial genera and 2 unclassified) differed significantly between periodontal and peri-implant health in at least one study, and 52 taxa (27 bacterial species, 22 bacterial genera, 1 fungus, 1 virus and 1 unclassified) differed significantly between periodontitis and peri-implantitis in at least one study. Three studies found no statistically significant differences for any taxa between health implants/teeth or diseased implants/teeth. . $3,24,26^{2}$

No taxa presented Strong, Moderate or Mild/Some evidence for a specific association with peri-implantitis in comparison with periodontitis, or for peri-implant health in comparison with periodontal health, based on the criteria defined by Perez-Chaparro et al. ${ }^{12}$

\section{Risk of bias within studies}

Table 7 shows the risk of bias analysis of the studies included in this systematic review, according to the NIH Quality Assessment Tool for Observational Cohort and Cross-Sectional Studies. All articles explicitly defined a research question (Item \#1), the population from which the study participants were selected (Item \#2), recruited more than $50 \%$ of the target population (Item \#3), defined - in detail - the exposure measures and assessments (Item \#9), elucidated the 


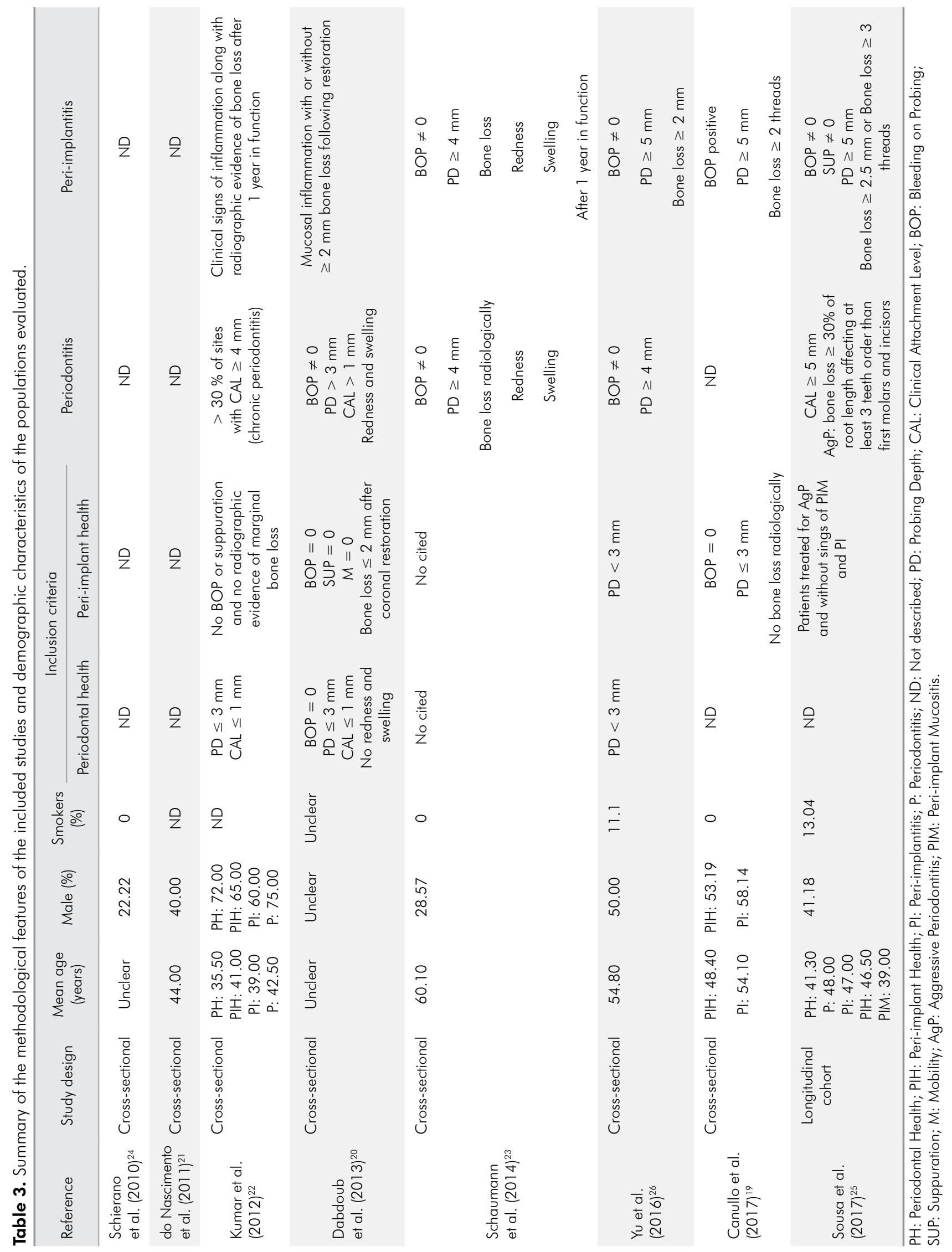


Does subgingival bacterial colonization differ between implants and teeth? A systematic review

Table 4. Clinical characteristics of the study volunteers.

\begin{tabular}{|c|c|c|c|c|c|c|}
\hline \multirow{2}{*}{ Reference } & \multirow{2}{*}{$\begin{array}{l}\text { Mean plaque } \\
\text { index }\end{array}$} & \multirow{2}{*}{ Mean PD } & \multirow{2}{*}{ Mean CAL } & \multicolumn{3}{|c|}{ Number of sites } \\
\hline & & & & $\mathrm{PD} \geq 5 \mathrm{~mm}$ & $\mathrm{PD} \geq 6 \mathrm{~mm}$ & $\mathrm{PD} \geq 7 \mathrm{~mm}$ \\
\hline Schierano et al. $(2010)^{24}$ & Not cited & Not cited & Not cited & Not cited & Not cited & Not cited \\
\hline do Nascimento et al. $(2011)^{21}$ & Not cited & Not cited & Not cited & Not cited & Not cited & Not cited \\
\hline Kumar et al. $(2012)^{22}$ & Not cited & $\begin{array}{c}\mathrm{PH}: 2.4 \pm 1.9 \\
\mathrm{P}: 7.5 \pm 3.5 \\
\mathrm{Pl}: 3.2 \pm 1.7 \\
\mathrm{PH}: 6.0 \pm 3.5\end{array}$ & $\begin{array}{c}\mathrm{PH}: 0.8 \pm 0.7 \\
\mathrm{P}: 6.7 \pm 2.9 \\
\text { Not cited } \\
\text { Not cited }\end{array}$ & Not cited & Not cited & Not cited \\
\hline Dabdoub et al. $(2013)^{20}$ & Not cited & Not cited & Not cited & Not cited & Not cited & Not cited \\
\hline Schaumann et al $(2014)^{23}$ & $\begin{array}{l}\text { P: } 28.6 \pm 39.3 \\
P I: 35.7 \pm 37.8\end{array}$ & $\begin{array}{l}\text { P: } 4.1 \pm 1.3 \\
P I: 5.0 \pm 1.3\end{array}$ & Not cited & Not cited & Not cited & Not cited \\
\hline Yu et al. $(2016)^{26}$ & Not cited & $\begin{array}{c}\mathrm{PH}: 2.22 \pm 0.73 \\
\text { P: } 5.44 \pm 1.15 \\
\mathrm{PI}: 3.00 \pm 0.77 \\
\mathrm{PIH}: 8.11 \pm 1.64\end{array}$ & Not cited & Not cited & Not cited & Not cited \\
\hline Canullo et al. $(2017)^{19}$ & $\begin{array}{c}\mathrm{PIH}: 0.87 \pm 0.55 \\
\mathrm{PI}: 3.88 \pm 1.45\end{array}$ & $\begin{array}{c}\mathrm{PIH}: 1.83 \pm 1.62 \\
\mathrm{PI}: 5.71 \pm 1.43\end{array}$ & $\begin{array}{c}\mathrm{PIH}: 0.00 \pm 0.00 \\
\mathrm{Pl}: 4.15 \pm 0.97\end{array}$ & Not cited & Not cited & Not cited \\
\hline Sousa et al. $(2017)^{25}$ & Not cited & Not cited & Not cited & Not cited & Not cited & Not cited \\
\hline
\end{tabular}

PD: Probing Depth; CAL: Clinical Attachment Level; PH: Periodontal Health; PIH: Peri-implant Health; Pl: Peri-implantitis; P: Periodontitis.

Table 5. Methodological features of sample collection and analysis.

\begin{tabular}{|c|c|c|c|c|c|c|c|}
\hline \multirow{2}{*}{ Reference } & \multicolumn{4}{|c|}{ n samples } & \multirow{2}{*}{$\begin{array}{l}\text { Sampling } \\
\text { strategy }\end{array}$} & \multirow{2}{*}{ Diagnostic method } & \multirow{2}{*}{ Data expression } \\
\hline & $\mathrm{PH}$ & $P$ & $\mathrm{PI}$ & $\mathrm{PIH}$ & & & \\
\hline Schierano et al. $(2010)^{24}$ & 9 & - & - & 9 & Individual & Culture & CFU and frequency \\
\hline do Nascimento et al. $(2011)^{21}$ & 20 & - & - & 29 & Individual & Checkerboard DNA-DNA Hybridization & Count and proportion \\
\hline Kumar et al. $(2012)^{22}$ & 10 & 10 & 10 & 10 & Pool & Pyrosequencing & Abundance and diversity \\
\hline Dabdoub et al. $(2013)^{20}$ & 56 & 25 & 40 & 41 & Individual & Pyrosequencing & Abundance and diversity \\
\hline Schaumann et al. $(2014)^{23}$ & - & $7^{*}$ & $7^{*}$ & - & Pool & Sequencing & Abundance and diversity \\
\hline Yu et al. $(2016)^{26}$ & 18 & 18 & 18 & 18 & Individual & Pyrosequencing & Abundance and diversity \\
\hline Canullo et al. $(2017)^{19}$ & - & 47 & 47 & 43 & Individual & RT-PCR & Count \\
\hline Sousa et al. $(2017)^{25}$ & 24 & 24 & 5 & 8 & Individual & Pyrosequencing & Abundance and diversity \\
\hline Total samples & 137 & 131 & 127 & 158 & & & \\
\hline
\end{tabular}

PH: Periodontal Health; P: Periodontitis; PI: Peri-implantitis; PIH: Peri-implant Health; CFU: Colony Forming Unit; RT-PCR: Real Time-Polymerase Chain Reaction. *Information was not clear in the methodology description.

follow-up rate (Item \#13) and conducted the statistical analyses (Item \#14). Only 7 studies used previously determined eligibility criteria (Item \#4), and only one presented sample size justification (Item \#5). No study complied with the following Items: \#6 (Exposure assessed prior to outcome measurement), \#7 (Sufficient timeframe to see an effect), \#10 (Repeated exposure assessment) and \#12 (Blinding of outcome assessors) of the NIH Quality Assessment Tool. Three studies showed different levels of the exposure of interest (Item \#8), and six studies defined the outcomes in details (Item \#11).

None of the included articles fulfilled all items of the NIH Quality Assessment Tool. Three articles complied with 9 items; another 3 , with 8 items, and 2 articles with 7 items. Thus, all articles included in this review accomplished at least $50 \%$ of the items assessed. 
Table 6. Microorganisms found in statistically significantly higher counts/proportions/abundance/prevalence in the different periodontal and peri-implant conditions.

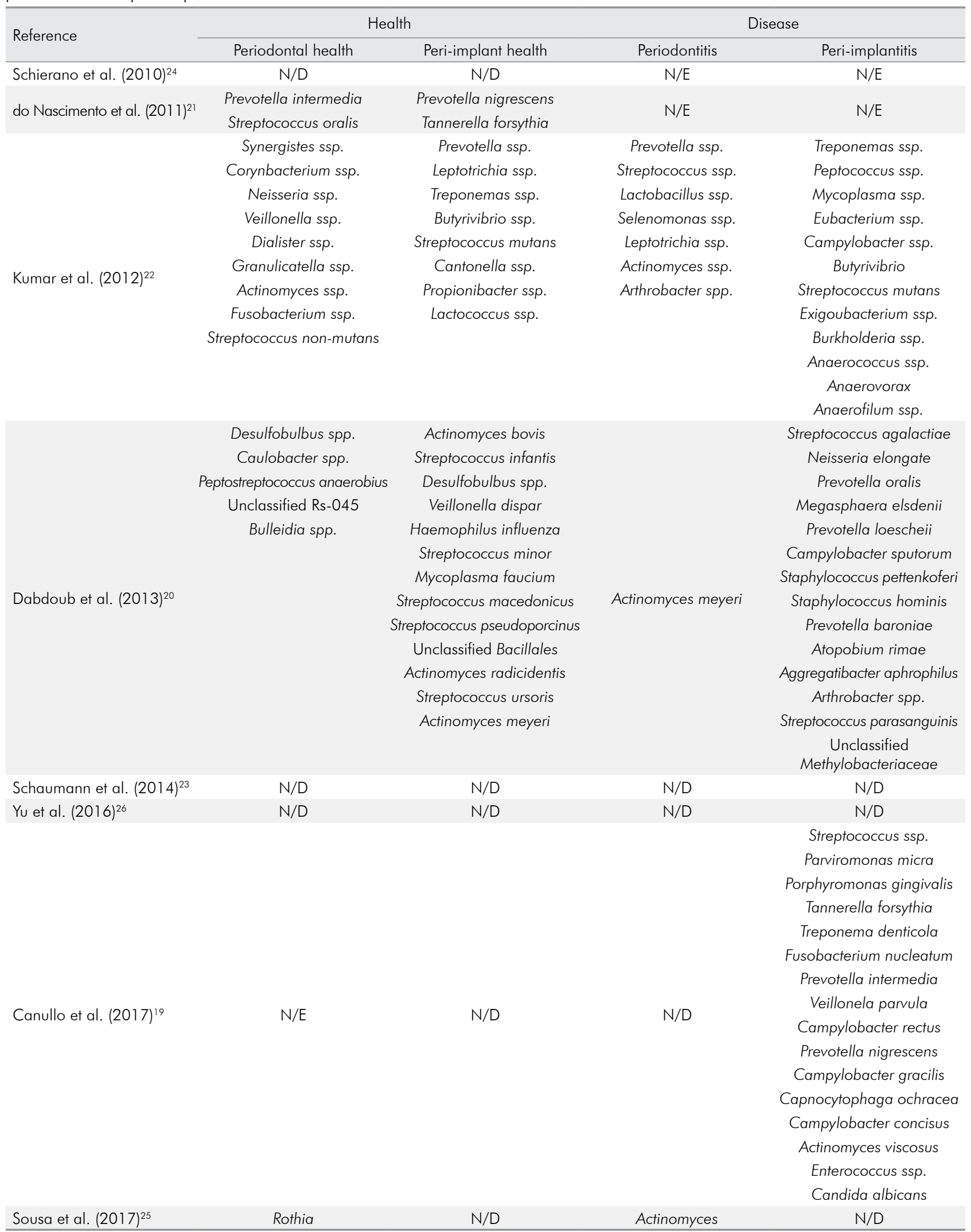

N/E: Not Evaluated; N/D: No Differences 
Table 7. Quality assessment of the included studies according to the NIH Quality Assessment Tool for Observational Cohort and Cross-Sectional Studies.

\begin{tabular}{|c|c|c|c|c|c|c|c|c|c|}
\hline \multirow[b]{2}{*}{ Question } & \multirow[b]{2}{*}{$\begin{array}{c}\text { Schierano } \\
\text { et al. }(2010)^{24}\end{array}$} & \multicolumn{7}{|c|}{ References } & \multirow[b]{2}{*}{ Total } \\
\hline & & $\begin{array}{l}\text { do Nascimento } \\
\text { et al. }(2011)^{21}\end{array}$ & $\begin{array}{l}\text { Kumar et al. } \\
(2012)^{22}\end{array}$ & $\begin{array}{l}\text { Dabdoub } \\
\text { et al. }(2013)^{20}\end{array}$ & $\begin{array}{l}\text { Schaumann } \\
\text { et al. }(2014)^{23}\end{array}$ & $\begin{array}{l}\text { Yu et al. } \\
(2016)^{26}\end{array}$ & $\begin{array}{l}\text { Canullo et } \\
\text { al. }(2017)^{19}\end{array}$ & $\begin{array}{l}\text { Sousa et al. } \\
(2017)^{25}\end{array}$ & \\
\hline $\begin{array}{l}\text { 1. Research } \\
\text { question }\end{array}$ & Yes & Yes & Yes & Yes & Yes & Yes & Yes & Yes & 8 \\
\hline $\begin{array}{l}\text { 2. Study } \\
\text { population }\end{array}$ & Yes & Yes & Yes & Yes & Yes & Yes & Yes & Yes & 8 \\
\hline $\begin{array}{l}\text { 3. Participant } \\
\text { rate of eligible } \\
\text { persons }\end{array}$ & Yes & Yes & Yes & Yes & Yes & Yes & Yes & Yes & 8 \\
\hline $\begin{array}{l}\text { 4. Eligibility } \\
\text { criteria }\end{array}$ & $C D$ & Yes & Yes & Yes & Yes & Yes & Yes & Yes & 7 \\
\hline 5. Sample size & No & No & No & No & No & No & No & Yes & 1 \\
\hline $\begin{array}{l}\text { 6. Exposure } \\
\text { assessment }\end{array}$ & No & No & No & No & No & No & No & No & 0 \\
\hline 7. Timeframe & No & No & No & No & No & No & No & No & 0 \\
\hline $\begin{array}{l}\text { 8. Exposure } \\
\text { levels }\end{array}$ & Yes & Yes & Yes & NA & NA & NA & No & NA & 3 \\
\hline $\begin{array}{l}\text { 9. Exposure } \\
\text { measures }\end{array}$ & Yes & Yes & Yes & Yes & Yes & Yes & Yes & Yes & 8 \\
\hline $\begin{array}{l}\text { 10. Repeated } \\
\text { exposure } \\
\text { assessment }\end{array}$ & No & No & No & No & No & No & No & No & 0 \\
\hline $\begin{array}{l}\text { 11. Outcomes } \\
\text { measures }\end{array}$ & Yes & Yes & Yes & Yes & Yes & No & No & Yes & 6 \\
\hline $\begin{array}{l}\text { 12. Assessors } \\
\text { blinding }\end{array}$ & No & No & No & No & No & No & No & No & 0 \\
\hline $\begin{array}{l}\text { 13. Follow-up } \\
\text { rate }\end{array}$ & Yes & Yes & Yes & Yes & Yes & Yes & Yes & Yes & 8 \\
\hline $\begin{array}{l}\text { 14. Statistical } \\
\text { analyses }\end{array}$ & Yes & Yes & Yes & Yes & Yes & Yes & Yes & Yes & 8 \\
\hline Total & 8 & 9 & 9 & 8 & 8 & 7 & 7 & 9 & \\
\hline
\end{tabular}

CD: cannot determine; NA: not applicable.

\section{Discussion}

The results of this systematic review indicated that there is insufficient evidence in the literature to support specific differences between the composition of the subgingival biofilm colonizing teeth and implants, either in disease (periodontitis versus peri-implantitis) or in health (healthy teeth versus healthy implants).

Although no previous studies have weighed the evidence for the existence of specific differences between the microbiota colonizing teeth and implants, the studies comparing healthy and diseased implants had previously shed light on the lack of striking differences between pathogens associated with peri-implantitis and periodontitis. ${ }^{27}$ A previous systematic review ${ }^{10}$ gathering data of all Association studies evaluating the composition of the biofilm surrounding healthy and diseased implants showed that the microbiota associated with peri-implantitis was predominantly dominated by recognized periodontal pathogens, such as $P$. gingivalis, T. denticola and T. forsythia.

The rationale for the existence of specific microorganisms colonizing different surfaces in the mouth is based on the concept established by Ron Gibbons and co-workers in the 1970's that oral bacteria adhere selectively to different surfaces in the oral cavity. Gibbons also showed that this specific adhesion was an ecological determinant for the establishment and distribution of bacteria on oral surfaces. ${ }^{28,29}$ The 
lack of differences between the microbiota colonizing implants and teeth in the present study suggest that the initial colonizers of these two structures probably do not differ substantially. In addition, the fact that they are sheltered in a very similar environment (periodontal or peri-implant sulcus/pocket); are exposed to the same fluids (crevicular fluid and saliva), similar nutritional conditions and redox potential, may also contribute to the establishment of similar biofilms. Thus, although there are important structural differences between periodontal and peri-implant surfaces that translate into some differences in host response $^{30}$, these differences may not be sufficient to generate distinct microbial profiles. Based on the widely recognized concept that peri-implantitis and periodontitis are associated with a microbial challenge $\mathrm{e}^{1,31}$ and the data of the present study that there are no recognized differences between the microbiota of diseased teeth and implants, it could be hypothesized that the anti-infective treatments of peri-implantitis and periodontitis would also be similar. Nonetheless, points of consideration in this line of thought are the difficulties associated with the disinfection of irregular implant surfaces..$^{32}$.

An interesting information provided by this systematic review was the high number of studies using sequencing/pyrosequencing ( 5 of the 8 articles included), which provided comprehensive data for several bacterial taxonomic levels (e.g., species, genus, phylum), viruses, fungi and parasites. ${ }^{33} \mathrm{In}$ addition, this type of analysis may detect unclassified microorganisms or uncultured bacterial species that could be associated with periodontal/peri-implant health or disease. Another important point of discussion refers to the different inclusion criteria used to define the clinical conditions evaluated: periodontal and peri-implant health, periodontitis and peri-implantitis (Table 3). This lack of standardization probably occurred due to some difficulties associated with the use of the 1999 Classification System for Periodontal Disease and Conditions ${ }^{34}$ and the lack of consensus about the definition of peri-implant diseases. It is expected that the recently published Classification of Periodontal and Peri-implant Diseases and Conditions ${ }^{1,31}$ will help to standardize future studies evaluating these clinical conditions.

The main limitation of this systematic review was the inclusion of studies using different microbiological diagnostic tests, data expression (counts/proportions/abundance/prevalence) and inclusion/exclusion criteria. The main strength is that it is the first study to assess the current weight of evidence concerning specific differences in the composition of the subgingival/submucosal microbiota colonizing teeth and implants surfaces, respectively.

In conclusion, the results of this systematic review indicated that there is insufficient evidence in the literature to support specific differences between microorganisms colonizing teeth and implants, either in health or in disease.

\section{Acknowledgements}

The authors would like to thank Capes (Brazilian Federal Agency for Support and Evaluation of Graduate Education within the Ministry of Education of Brazil) and Latin American Oral Health Association (LAOHA) for supporting different researchers involved in this study.

\section{References}

1. Berglundh T, Armitage G, Araujo MG, Avila-Ortiz G, Blanco J, Camargo PM, et al. Peri-implant diseases and conditions: Consensus report of workgroup 4 of the 2017 World Workshop on the Classification of Periodontal and Peri-Implant Diseases and Conditions. J Periodontol. 2018 Jun;89 Suppl 1:S313-8. https://doi.org/10.1002/JPER.17-0739

2. Derks J, Tomasi C. Peri-implant health and disease. A systematic review of current epidemiology. J Clin Periodontol. 2015 Apr;42 Suppl 16:S158-71. https://doi.org/10.1111/icpe.12334

3. Derks J, Schaller D, Hakansson J, Wennstrom JL, Tomasi C, Berglundh T. Effectiveness of implant therapy analyzed in a swedish population: prevalence of peri-implantitis. J Dent Res. 2016 Jan;95(1):43-9. https://doi.org/10.1177/0022034515608832

4. Salvi GE, Cosgarea R, Sculean A. Prevalence and mechanisms of peri-implant diseases. J Dent Res. 2017 Jan;96(1):31-7. https://doi.org/10.1177/0022034516667484 
5. Meijndert L, van der Reijden WA, Raghoebar GM, Meijer HJ, Vissink A. Microbiota around teeth and dental implants in periodontally healthy, partially edentulous patients: is pre-implant microbiological testing relevant? Eur J Oral Sci. 2010 Aug;118(4):357-63. https://doi.org/10.1111/j.1600-0722.2010.00750.x

6. Monje A, Wang HL, Nart J. Association of preventive maintenance therapy compliance and peri-implant diseases: a cross-sectional study. J Periodontol. 2017 Oct;88(10):1030-41. https://doi.org/10.1902/jop.2017.170135

7. Ata-Ali J, Flichy-Fernández AJ, Alegre-Domingo T, Ata-Ali F, Palacio J, Peñarrocha-Diago M. Clinical, microbiological, and immunological aspects of healthy versus peri-implantitis tissue in full arch reconstruction patients: a prospective cross-sectional study. BMC Oral Health. 2015;15(1):1-10. https://doi.org/10.1186/s12903-015-0031-9

8. Wang HL, Garaicoa-Pazmino C, Collins A, Ong HS, Chudri R, Giannobile WV. Protein biomarkers and microbial profiles in peri-implantitis. Clin Oral Implants Res. 2016 Sep;27(9):1129-36. https://doi.org/10.1111/clr.12708

9. Stokman MA, van Winkelhoff AJ, Vissink A, Spijkervet FK, Raghoebar GM. Bacterial colonization of the peri-implant sulcus in dentate patients: a prospective observational study. Clin Oral Investig. 2017 Mar;21(2):717-24. https://doi.org/10.1007/s00784-016-1941-x

10. Pérez-Chaparro PJ, Duarte PM, Shibli JA, Montenegro S, Lacerda Heluy S, Figueiredo LC, et al. The current weight of evidence of the microbiologic profile associated with peri-implantitis: a systematic review. J Periodontol. 2016;87(11):1295-304.

11. Moher D, Liberati A, Tetzlaff J, Altman DG. PRISMA Group. Preferred reporting items for systematic reviews and meta-analyses: the PRISMA statement. PLoS Med. 2009 Jul;6(7):e1000097. https://doi.org/10.1371/journal.pmed.1000097

12. Pérez-Chaparro PJ, Gonçalves C, Figueiredo LC, Faveri M, Lobão E, Tamashiro N, et al. Newly identified pathogens associated with periodontitis: a systematic review. J Dent Res. 2014;93(9):846-58. https://doi.org/10.1177/0022034514542468

13. Apatzidou D, Lappin DF, Hamilton G, Papadopoulos CA, Konstantinidis A, Riggio MP. Microbiome of peri-implantitis affected and healthy dental sites in patients with a history of chronic periodontitis. Arch Oral Biol. 2017 Nov;83(July):145-52. https://doi.org/10.1016/i.archoralbio.2017.07.007

14. Nelson S, Thomas G. Bacterial persistence in dentoalveolar bone following extraction: a microbiological study and implications for dental implant treatment. Clin Implant Dent Relat Res. 2010 Dec;12(4):306-14. https://doi.org/10.1111/i.1708-8208.2009.00165.x

15. Liu Y, Yang H, Wen Y, Li B, Zhao Y, Xing J, et al. Nrf2 Inhibits Periodontal Ligament Stem Cell Apoptosis under Excessive Oxidative Stress. Int J Mol Sci. 2017 May;18(5):E1076. https://doi.org/10.3390/ijms18051076

16. Zhang $Q$, Qin XY, Jiang WP, Zheng $H, X u X L$, Chen F. Comparison of subgingival and peri-implant microbiome in chronic periodontitis. Chin J Dent Res. 2015 Sep;18(3):155-62. Available from: http://www.ncbi.nlm.nih.gov/pubmed/26485507

17. Koyanagi T, Sakamoto M, Takeuchi Y, Maruyama N, Ohkuma M, Izumi Y. Comprehensive microbiological findings in peri-implantitis and periodontitis. J Clin Periodontol. 2013 Mar;40(3):218-26. https://doi.org/10.1111/icpe.12047

18. Koyanagi T, Sakamoto M, Takeuchi Y, Ohkuma M, Izumi Y. Analysis of microbiota associated with peri-implantitis using $16 \mathrm{~S}$ rRNA gene clone library. J Oral Microbiol. 2010 May;2(2):1-8. https://doi.org/10.3402/jom.v2i0.5104

19. Canullo L, Radovanović S, Delibasic B, Blaya JA, Penarrocha D, Rakic M. The predictive value of microbiological findings on teeth, internal and external implant portions in clinical decision making. Clin Oral Implants Res. 2017 May;28(5):512-9. https://doi.org/10.1111/clr.12828

20. Dabdoub SM, Tsigarida AA, Kumar PS. Patient-specific analysis of periodontal and peri-implant microbiomes. J Dent Res. 2013 Dec;92(12 Suppl):168S-75S. https://doi.org/10.1177/0022034513504950

21. do Nascimento C, Monesi N, Ito IY, Issa JP, de Albuquerque Junior RF. Bacterial diversity of periodontal and implant-related sites detected by the DNA Checkerboard method. Eur J Clin Microbiol Infect Dis. 2011 Dec;30(12):1607-13. https://doi.org/10.1007/s10096-011-1267-1

22. Kumar PS, Mason MR, Brooker MR, O'Brien K. Pyrosequencing reveals unique microbial signatures associated with healthy and failing dental implants. J Clin Periodontol. 2012 May;39(5):425-33. https://doi.org/10.1111/j.1600-051X.2012.01856.x

23. Schaumann S, Staufenbiel I, Scherer R, Schilhabel M, Winkel A, Stumpp SN, et al. Pyrosequencing of supra- and subgingival biofilms from inflamed peri-implant and periodontal sites. BMC Oral Health. 2014 Dec;14(1):157. https://doi.org/10.1186/1472-6831-14-157

24. Schierano G, Pejrone G, Roana J, Scalas D, Allizond V, Martinasso G, et al. A split-mouth study on microbiological profile in clinical healthy teeth and implants related to key inflammatory mediators. Int J Immunopathol Pharmacol. 2010 Jan-Mar;23(1):279-88. https://doi.org/10.1177/039463201002300126

25. Sousa V, Nibali L, Spratt D, Dopico J, Mardas N, Petrie A, et al. Peri-implant and periodontal microbiome diversity in aggressive periodontitis patients: a pilot study. Clin Oral Implants Res. 2017 May;28(5):558-70. https://doi.org/10.1111/clr.12834

26. Yu XL, Chan Y, Zhuang LF, Lai HC, Lang NP, Lacap-Bugler DC, et al. Distributions of Synergistetes in clinically-healthy and diseased periodontal and peri-implant niches [Internet]. Microb Pathog. 2016 May;94:90-103. https://doi.org/10.1016/i.micpath.2015.11.029

27. Shibli JA, Melo L, Ferrari DS, Figueiredo LC, Faveri M, Feres M. Composition of supra- and subgingival biofilm of subjects with healthy and diseased implants. Clin Oral Implant Res [Internet]. 2008;19(10):975-82. https://doi.org/10.1111/j.1600-0501.2008.01566.x

28. Gibbons RJ, Houte J. Selective bacterial adherence to oral epithelial surfaces and its role as an ecological determinant. Infect Immun. 1971 Apr;3(4):567-73.

29. Liljemark WF, Gibbons RJ. Ability of Veillonella and Neisseria species to attach to oral surfaces and their proportions present indigenously. Infect Immun. 1971 Sep;4(3):264-8. PMID:5154885 
30. Heitz-Mayfield LJ, Lang NP. Comparative biology of chronic and aggressive periodontitis vs. peri-implantitis. Periodontol 2000. 2010 Jun;53(1):167-81.

31. Papapanou PN, Sanz M, Buduneli N, Dietrich T, Feres M, Fine DH, et al. Periodontitis: Consensus report of workgroup 2 of the 2017 World Workshop on the Classification of Periodontal and Peri-Implant Diseases and Conditions [Internet]. J Periodontol. 2018 Jun;89 Suppl 1:S173-82. https://doi.org/10.1002/JPER.17-0721

32. Valderrama P, Wilson TG Jr. Detoxification of implant surfaces affected by peri-implant disease: an overview of surgical methods. Int J Dent. 2013;2013:740680. https://doi.org/10.1155/2013/740680

33. Slots J. Periodontitis: facts, fallacies and the future. Periodontol 2000. 2017 Oct;75(1):7-23. https://doi.org/10.1111/prd.12221

34. Armitage GC. Development of a classification system for periodontal diseases and conditions. Ann Periodontol. 1999 Dec;4(1):1-6. https://doi.org/10.1902/annals.1999.4.1.1 